\title{
Synthesis and crystal structures of cofacial bischlorin. Octaethylchlorin-based structural models for the special pair in photosynthesis
}

\author{
Mathias O. Senge, ${ }^{* a}$ Werner W. Kalisch ${ }^{a}$ and Karin Ruhlandt-Senge ${ }^{* b}$ \\ a Institut für Organische Chemie (WE 02), Freie Universität Berlin, Takustr. 3, D-14195 Berlin, Germany \\ ${ }^{b}$ Department of Chemistry, Syracuse University, Syracuse, NY 13244, USA
}

\begin{abstract}
McMurry coupling of metalloformyloctaethylchlorins yields the first cofacial bischlorin with structural characteristics mimicking those of the special pair in photosynthesis.
\end{abstract}

Owing to their structural similarity to the 'special pair' in the photosynthetic reaction centre, cofacial chlorin dimers serve as biomimetic models to investigate the primary steps of photosynthesis, charge separation and electron transfer. ${ }^{1,2}$ In order to fully understand the photophysical behaviour of such compounds, detailed information on their conformation and the relative spatial arrangement of the subunits is necessary; ideally the geometry of such dimers should be as close as possible to the situation in vivo, i.e. cofacial structure with parallel ring orientation and partial overlap of the $\pi$ systems. Several bistetrapyrrole systems showing such features have been described, ${ }^{2-4}$ however, detailed information is available only for cofacial bisporphyrins while most bischlorin dimers exhibit an extended linear conformation. ${ }^{5-7}$ Here we report on the synthesis and first crystal structures of cofacial bischlorins based on octaethylchlorin (OEC).

A versatile synthesis of bisporphyrins through McMurry coupling 8 of formylporphyrins was developed by Smith and coworkers. ${ }^{4,7,9}$ The expected product of the reaction was the trans ethene-linked bisporphyrin but subsequent studies showed that this method gives convenient access to cofacial bisporphyrins since intramolecular $\pi-\pi$-aggregation leads to the predominant formation of the $c$ is ethene product. ${ }^{4}$ However, steric demand plays an important role as shown by the coupling of formylphytochlorins which led only to the formation of trans ethene-linked bischlorins. ${ }^{7}$ This prompted us to investigate the possibility if structural and functional chlorin-based models of the special pair are accessible via a similar route using transoctaethylchlorin (OEC) as starting material.

The McMurry products of metallo 5-formyloctaethylchlorins $^{5 a}$ prepared via Vilsmeier formylation of the respective metallo octaethylchlorins were expected to be quite different compared to the corresponding porphyrins since $\mathrm{sp}^{3}$ hybridization in the reduced pyrrole ring makes the chlorin subunits more sterically demanding. Nevertheless, low-valent titaniuminduced coupling of 1a yielded three green fractions in a combined yield of $90 \%$. The compounds were filtered through ALOX, evaporated under high vacuum and purified by column chromatography on neutral Aluminia Brockmann grade III using hexane-1\% thf as eluent. Spectroscopic and crystallographic analyses revealed the products to be a single cis ethene bischlorin $2 \div$ (Fig. 1) $\left[\lambda_{\max }\left(\mathrm{CH}_{2} \mathrm{Cl}_{2}\right) 411,463,665 \mathrm{~nm}\right]$ and two different atropisomers of trans ethene bis-OEC $3\left[\lambda_{\max }\right.$ $\left.\left(\mathrm{CH}_{2} \mathrm{Cl}_{2}\right) 412,459,654 \mathrm{~nm}\right]$ and $4\left[\lambda_{\max }\left(\mathrm{CH}_{2} \mathrm{Cl}_{2}\right) 412,464,661\right.$ $\mathrm{nm}]$.

Compound 2 clearly shows a cis-ethene linkage and the cofacial arrangement of the two macrocycles, which are tilted against each other by $22.4^{\circ}$. The two chlorin rings show an interplanar separation of $3.900 \AA$, an $\mathrm{Ni} \cdots \mathrm{Ni}$ separation of 6.151 $\AA$ and a lateral shift of the metal centres of $4.77 \AA$ (parameters were calculated using the method given by Scheidt and Lee). ${ }^{10}$
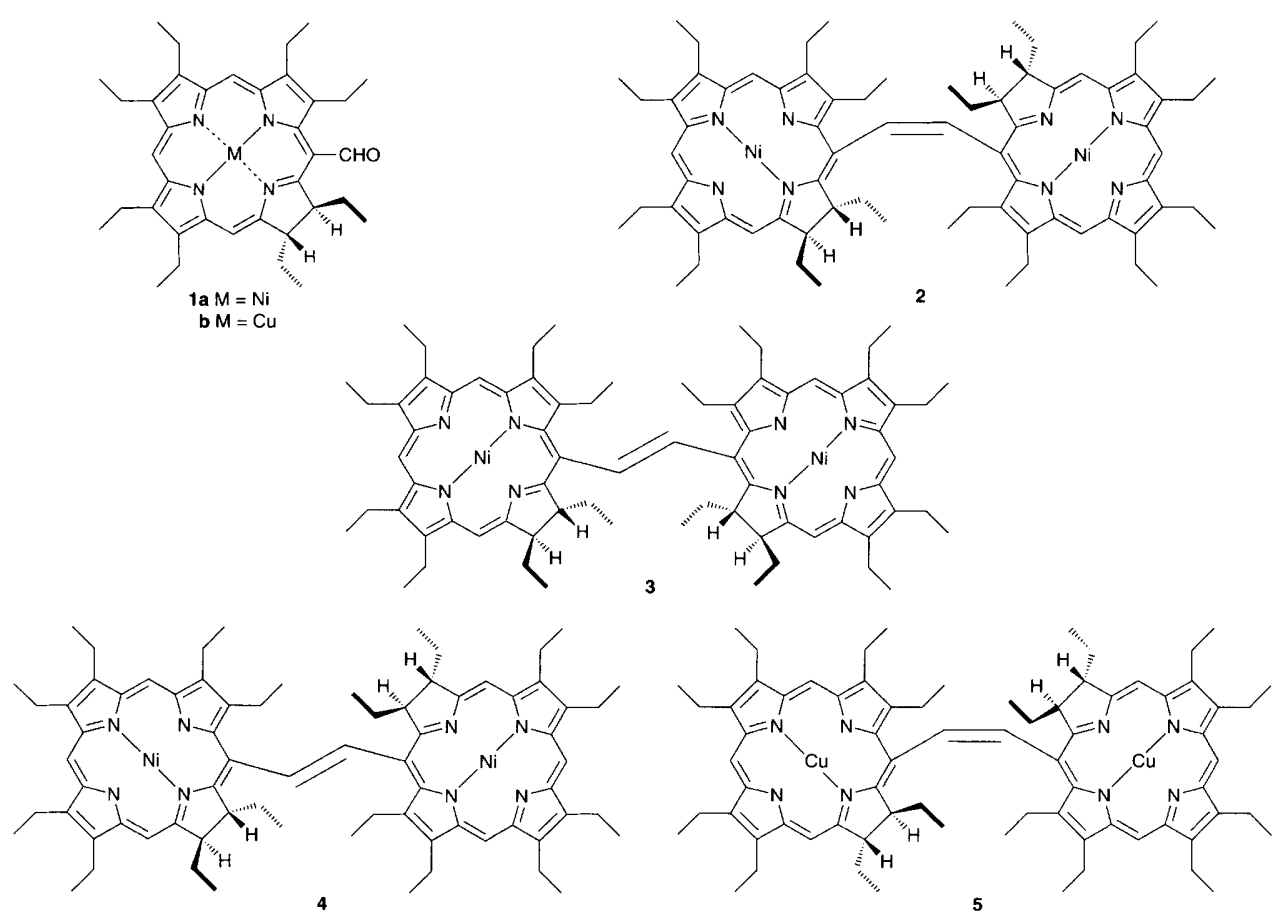

Chem. Commun., 1996 
Clearly, the relative orientation of the subunits is stabilized by intramolecular $\pi-\pi$-aggregation as evidenced by the significant overlap of the $\pi$ systems. This intramolecular aggregation is observed despite the fact that ruffling induced by the small ionic radius of the $\mathrm{Ni}^{\mathrm{II}}$ leads to significantly nonplanar macrocycles which, together with the reduced pyrrole ring, makes the individual macrocycles sterically much more demanding than the corresponding bisporphyrins. Thus, the larger steric demand in cis-NiOEC-CH=CH-NiOEC resulted in a more widened aggregate structure than the corresponding bisporphyrin cisNiOEP-CH=CH-NiOEP. ${ }^{4,9 b}$ Nevertheless, the bischlorin 2 presents a much better structural model for the special pair in the photosynthetic reaction centre since the cofacial macrocycle arrangement with overlap of only two pyrrole units and intermediate interplanar separation mimicks much more closely the situation found in vivo. ${ }^{1} \mathrm{H}$ NMR spectroscopy indicated that the structures found in the crystal are retained in solution.

Preliminary results with $\mathrm{Cu}^{\mathrm{II}} 5$-formyl-OEC $1 \mathrm{~b}$ indicate a larger product variety in the $\mathrm{Cu}^{\mathrm{II}}$ series. While most of the $\mathrm{Cu}^{\mathrm{II}}$ products are closely related to the structures observed in the $\mathrm{NiII}$ series, the structure of $c i s-\mathrm{CuOEC}-\mathrm{CH}=\mathrm{CH}-\mathrm{CuOEC} 5$ exhibits a gable-type, cofacial arrangement of the macrocycles without intramolecular aggregation (Fig. 2) $\dagger$

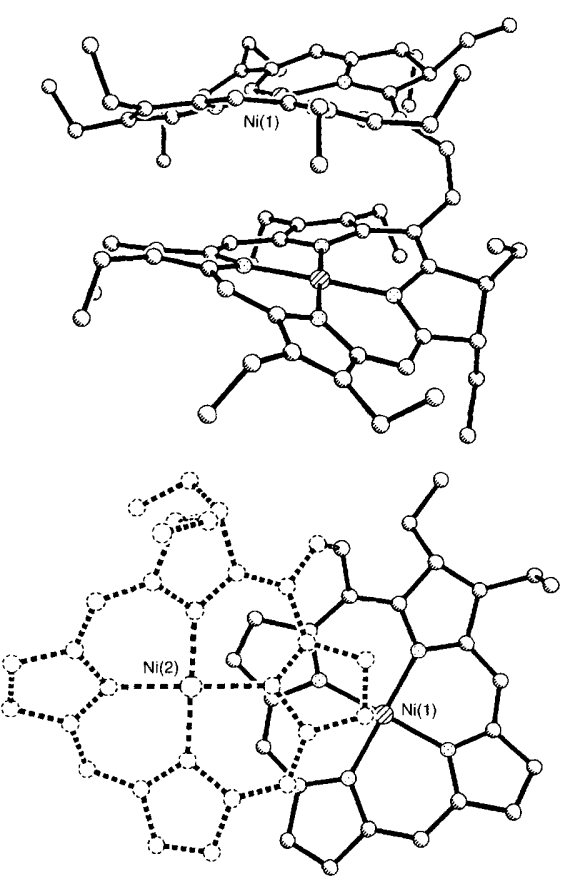

Fig. 1 Side and top view of the structure of $\mathbf{2}$ in the crystal. Hydrogen atoms and (in the bottom view) pyrrole ethyl side chains have been omitted for clarity.

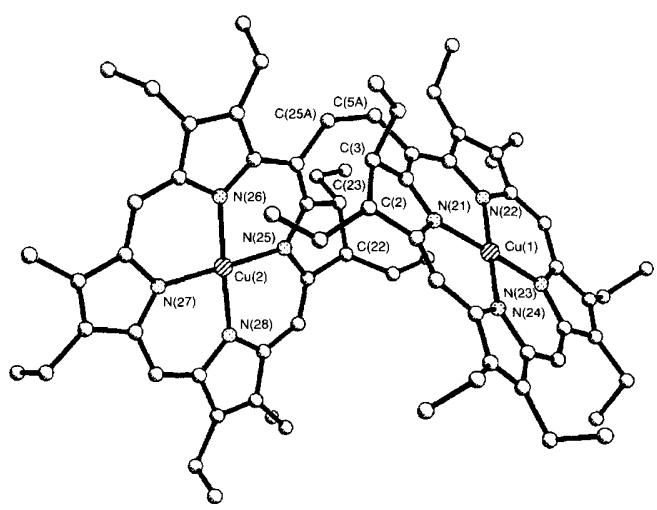

Fig. 2 Structure of $\mathbf{5}$ in the crystal. Hydrogen atoms have been omitted for clarity.
The two quite different structures observed for $\mathbf{2}$ and $\mathbf{5}$ clearly indicate the influence of steric constraints imposed by the reduced pyrrole ring in the different atropisomers on the aggregation properties. Thus, variation of the central metal in the McMurry coupling of formyl-OEC and different geometric constraints in the various isomers leads to considerably variability in the products obtained and provides convenient access to a number of bischlorins structurally closely related to the special pair in photosynthesis.

This work was supported by grants from the Deutsche Forschungsgemeinschaft, the Fonds der chemischen Industrie (MOS); Syracuse University, the National Science Foundation (CHE-9409446) and the Petroleum Research Fund (PRF28361-G3) (KRS). We are indebted to Professor K. M. Smith for his support and providing instrument time at the UC Davis crystallographic facility.

\section{Footnote}

$\dagger$ Crystal data: $130 \mathrm{~K}, \mathrm{Cu}-\mathrm{K} \alpha$ radiation $(\lambda=1.54178 \AA)$, structure solution via Patterson syntheses, refinement against $\left|F^{2}\right|$. (a) 2: $\mathrm{C}_{74} \mathrm{H}_{92} \mathrm{~N}_{8} \mathrm{Ni}_{2}$, triclinic, space group $P \overline{1}, a=13.446(3), b=14.761(4), c=17.064(5) \AA$, $\alpha=94.67(2), \beta=95.40(2), \gamma=104.89(2)^{\circ}, U=3239(2) \AA^{3}, Z=2$, $D_{c}=1.242 \mathrm{~g} \mathrm{~cm}^{-3}, \theta_{\max }=56^{\circ}, 8467$ independent reflections, 760 parameters, $R 1=0.062[I>2.0 \sigma(I)], R 1=0.0822, w R 2=0.1675$ (all data). (b) 5: $\mathrm{C}_{74} \mathrm{H}_{92} \mathrm{Cu}_{2} \mathrm{~N}_{8} \cdot \mathrm{CH}_{2} \mathrm{Cl}_{2}$, monoclinic, space group $P 2_{\mathrm{l}} / \mathrm{c}$, $a=19.154(7), b=12.808(5), c=28.280(11) \AA, \beta=98.39(3)^{\circ}$, $U=6864(5) \AA^{3}, Z=4, D_{\mathrm{c}}=1.263 \mathrm{~g} \mathrm{~cm}^{-3}, \theta_{\max }=52^{\circ}, 7376$ independent reflections, 559 parameters, $R 1=0.096[I>2.00(I)], R 1=0.1779$, $w R 2=0.2782$ (all data), solvent molecule and some ethyl side chains disordered. Atomic coordinates, bond lengths and angles, and thermal parameters have been deposited at the Cambridge Crystallograpic Data Centre (CCDC). See Information for Authors, Issue No. 1. Any request to the CCDC for this material should quote the full literature citation and the reference number $182 / 200$.

\section{References}

1 H. Michel, O. Epp and J. Deisenhofer, EMBO J., 1986, 5, 2445.

2 Reviews: M. R. Wasilewski, Chem Rev, 1992, 92, 435; in The Photosynthetic Reaction Center, ed. D. Deisenhofer and J. R. Norris, Academic Press, New York, 1993, vol. II, p. 465; D. Gust and T. A. Moore, Top. Curr. Chem., 1991, 159, 103.

3 Selected examples: M. H. Hatada, A. Tulinsky and C. K. Chang, J. Am. Chem. Soc., 1980, 102, 7116; J. P. Collman, A. O. Chong, G. B. Jameson, R. T. Oakley, E. Rose, E. Schmittou and J. A. Ibers, J. Am. Chem. Soc., 1981, 103, 516; G. M. Dubowchik and A. D. Hamilton, J. Chem. Soc., Chem. Commun., 1986, 1391; A. Osuka, S. Nakajima, T. Okada, S. Taniguchi, K. Nozaki, T. Ohno, I. Yamazaki, Y. Nishimura and N. Magata, Angew. Chem., Int. Ed. Engl., 1996, 35, 92; H. Meier, Y. Kobuke and S.-I. Kugimiya, J. Chem. Soc., Chem. Commun. 1989, 923; C. A. Hunter, M. N. Meah and J. K. M. Sanders, J. Am. Chem. Soc., 1990, 112, 5773; C. M. Drain, R. Fischer, E. G. Nolen and J.-M. Lehn, J. Chem. Soc, Chem. Commun., 1993, 243; G. V. Ponomarev, V. V. Borovkov, K.-i. Sugiura, Y. Sakata and A. M. Shul'ga, Tetrahedron Lett., 1993, 34, 2153; S. Anderson, H. L., Anderson, A. Bashall, M. McPartlin and J. K. M. Sanders, Angew. Chem., Int. Ed. Engl., 1995, 34, 1096

4 M. O. Senge, K. R. Gerzevske, M. G. H. Vicente, T. P. Forsyth and K. M. Smith, Angew. Chem., Int. Ed. Engl., 1993, 32, 750.

5 (a) K. M. Smith, G. M. F. Bisset and M. J. Bushell, Bioorg. Chem., $1980,9,1$; (b) M. O. Senge, H. Hope and K. M. Smith, J. Chem. Soc., Perkin Trans. 2, 1993, 11

6 M. R. Wasielewski, G. L. Gaines III, G. P. Wiederrecht, W. A. Svec and M. P. Niemczyk, J. Am. Chem. Soc., 1993, 115, 10442; G. P. Wiederrecht, M. P. Niemczyk, W. A. Svec and M. R. Wasielewski, J. Phys. Chem., 1996, 118, 81; and references therein.

7 L. Jaquinod, D. J. Nurco, C. J. Medforth, R. K. Pandey, T. P. Forsyth, M. M. Olmstead and K. M. Smith, Angew. Chem., Int. Ed. Engl., 1996, 35, 103 .

8 J. E. McMurry, Chem. Rev., 1989, 89, 1513.

9 (a) M. G. H. Vicente and K. M. Smith, Synlett, 1990, 579; J. Org. Chem., 1991, 56, 4407; (b) M. O. Senge, M. G. H. Vicente, K. R. Gerzevske, T. P. Forsyth and K. M. Smith, Inorg. Chem., 1994, 33, 5625 .

10 W. R. Scheidt and Y.-J. Lee, Struct. Bonding (Berlin), 1987, 64, 1.

Received, 6th June 1996; Com. 6/03965K 